\title{
¿HACIA UNA REFORMULACIÓN DE LA INVIOLABILIDAD DEL DOMICILIO?
}

\section{Towards a reformulation of the right to inviolability of the home?}

\author{
CRISTINA ZOCO ZABALA' \\ Universidad Pública de Navarra \\ cristina.zoco@unavarra.es
}



Resumen

En este trabajo se analiza el objeto protegido en la norma de derecho fundamental (art. 18.2 CE) y en la jurisprudencia del Tribunal Constitucional, así como su adecuación a los diferentes escenarios — pasados y presentes - en los que se despliega. Se verifica que el objeto protegido es la inviolabilidad del espacio físico, con independencia del carácter más o menos íntimo o privado de lo que acontece o anida en él. Asimismo, se evidencia una jurisprudencia constitucional más vinculada al destino del espacio físico — desarrollo de vida íntima o privada - que a su cualidad de inviolable. Se propone reformular el objeto iusfundamental con el fin de garantizar una protección que alcance todos los espacios definidos como inviolables, con independencia de su destino o la existencia efectiva de vida íntima o privada en ellos.

1 Este trabajo se ha realizado en el marco del Proyecto de $\mathrm{I}+\mathrm{D}$ «El nexo dato científico/ tecnológico-derecho fundamental: un desafío para los actuales ordenamientos constitucionales». Código PGC2018-093737-B-100. 


\title{
Palabras clave
}

Inviolabilidad; vida íntima; vida privada; privacidad del espacio físico; libertad personal; propiedad; libre desarrollo de la personalidad.

\begin{abstract}
This work analyzes the object protected in article 18.2 CE and in the jurisprudence of the Constitutional Court. Likewise, it verifies its adequacy to the different scenarios - past and present - in which it is applied. It is concluded that the protected object is the inviolability of the physical space, regardless of the more or less intimate or private character of what happens or what nests in such space; also regardless that nothing happens or is contained in it.

Likewise, a restrictive constitutional jurisprudence that protects the physical spaces in which intimate or private life takes place is revealed. In this sense, not all inviolable spaces are protected. It is proposed to reformulate the fundamental object enunciated in art. 18.2 CE in order to guarantee a more real and effective protection that reaches all spaces that are inviolable. This regardless of whether their natural destiny is not development of intimate life in them, or regardless of the effective existence of intimate or private life.
\end{abstract}

\section{Keywords}

Inviolability; privacy; privacy of physical space; personal freedom; property; free development of personality. 


\section{SUMARIO}

I. INTRODUCCIÓN. II. OBJETO PROTEGIDO POR EL ARTÍCULO 18.2 CE: LA INVIOLABILIDAD DEL ESPACIO FÍSICO: 1. Inviolabilidad e impenetrabilidad. 2. Domicilio constitucionalmente conforme y domicilio legal. III. UN DERECHO FUNDAMENTAL AUTÓNOMO: 1. Inviolabilidad del domicilio y derecho a la propiedad (art. 33.1 CE). 2. Inviolabilidad del domicilio y libertad personal (art. 17.1 CE). 3. Inviolabilidad del domicilio y libre desarrollo de la personalidad (art. 10.1 CE). IV. NATURALEZA FORMAL. V. CONCLUSIÓN. BIBLIOGRAFía.

\section{INTRODUCCIÓN}

La inviolabilidad del domicilio constituye el objeto de un derecho fundamental (art. 18.2 CE) cuyo enunciado limita su contenido a la posibilidad de intervenir tal espacio físico; bien sea mediante resolución judicial, por consentimiento de su titular, o tras la evidencia policial — visual o acústica — de la perpetración de hechos presuntamente delictivos (delito flagrante).

El art. 18.2 CE garantiza la intangibilidad del espacio físico en sí mismo considerado; ello con independencia del carácter más o menos íntimo de lo que transcurre en tal espacio, o al margen de que albergue datos de la vida íntima o privada de sus poseedores. Incluso, aunque nada acaezca o se contenga en él, pues el domicilio constitucionalmente conforme se identifica con su inviolabilidad ${ }^{2}$.

Ab initio, la jurisprudencia del Tribunal Constitucional vinculó de forma restrictiva el domicilio de las personas físicas con su presumible o efectivo destino - desarrollo de vida íntima o privada-, pero no con su carácter inviolable. Aunque extendió la protección al analizar las garantías de la delimitación restrictiva de algunos de estos espacios inviolables.

Posteriormente, los nuevos escenarios tecnológicos y procesos productivos especialmente agresivos, sobre todo en términos medioambientales, han estimulado una novedosa jurisprudencia del Tribunal Constitucional extendiendo el objeto protegido más allá de la dimensión negativa y formal que su enunciado reconoce. $\mathrm{Al}$ paso de la precedente jurisprudencia del Tribunal Europeo de Derechos Humanos, se acepta que constituye, además de un derecho de resistencia frente a la intervención

2 En este trabajo se verifica la identidad del domicilio constitucionalmente conforme con su inviolabilidad. En este sentido, se prescinde del análisis del «domicilio» protegido en las normas del ordenamiento infraconstitucional (civil, penal, administrativo, mercantil, o tributario). 
de terceros en el espacio domiciliar, una obligación de los poderes públicos de garantizar la vida privada conforme con el libre desarrollo de la personalidad.

Más recientemente, la existencia de dispositivos tecnológicos de largo alcance —aeronaves no tripuladas, micrófonos espía, SITEL—, o de medidas de investigación tecnológica (procedimientos de registros remotos de terminales informáticos), ha mostrado que lo protegido por el art. 18.2 CE alcanza la inviolabilidad del espacio físico en un sentido que dilata el concepto jurídico clásico subyacente del domicilio ${ }^{3}$.

Este trabajo revisa el objeto protegido en la norma de derecho fundamental y en la jurisprudencia del Tribunal Constitucional, así como su adecuación a los diferentes escenarios — pasados y presentes_. Y llama la atención sobre cierta jurisprudencia fluctuante en el análisis ad casum.

\section{OBJETO PROTEGIDO POR EL ARTÍCULO 18.2 CE: LA INVIOLABILIDAD DEL ESPACIO FÍSICO}

El art. 18.2 CE asegura la inviolabilidad de un espacio físico inmune a la invasión de terceros ${ }^{4}$. Constituye garantía formal de su intangibilidad, por lo que la sola intervención vulnera el objeto protegido.

3 «La inviolabilidad del domicilio es de contenido amplio e impone una extensa serie de garantías y de facultades, en las que se comprenden las de vedar toda clase de invasiones incluidas las que puedan realizarse sin penetración directa por medio de aparatos mecánicos, electrónicos u otros análogos»(STC 22/1984). El Tribunal Supremo ha señalado que la inviolabilidad del domicilio queda vulnerada por la interceptación a través de dispositivo tecnológico del espacio físico sin las debidas garantías (STS 329/2016, de 20 de abril, Sala de lo Penal, Sección 1.a).

4 La inviolabilidad del domicilio protege «la seguridad de un ámbito físico inmune a la entrada no querida de otros, en primer lugar, de las autoridades públicas, salvo con autorización judicial, pero no sólo de las autoridades públicas sino de cualquier otra persona, puesto que la eficacia horizontal de este derecho me parece difícilmente discutible» (Aragón Reyes, 1998: 352). En el mismo sentido, se ha señalado que identificar la intimidad como el bien jurídico protegido por la inviolabilidad del domicilio reduce la sustantividad de la inviolabilidad de domicilio, pues atribuye al art. 18.2 CE una función instrumental en relación con la intimidad: "[...] una función de tales características parece incompatible con la propia naturaleza de los derechos fundamentales, que no deben tener otro bien jurídico protegido que el que pueda deducirse de sus propios elementos» (Biglino Campos, 1997: XXI-XXII). En análogo sentido, se ha señalado que la inviolabilidad del domicilio constituye garantía formal de intangibilidad, por lo que el espacio (domicilio) es de acceso reservado en cuanto tal con independencia de cualquier consideración material (Díez-Picazo, 2021: 302). El art. 18.2 CE protege la facultad del titular de excluir a otros de ese 


\section{INVIOLABILIDAD E IMPENETRABILIDAD}

De lo anterior se colige que la inviolabilidad no solo alcanza la impenetrabilidad estrictamente física.

La revolución tecnológica está provocando nuevas exigencias de rendimiento del derecho al requerirle unas prestaciones garantistas de la inviolabilidad domiciliar en un sentido que dilata el concepto jurídico tradicional5. El art. 18.2 CE afronta nuevos escenarios consistentes en intervenciones sin la presencia física de los manipuladores de los dispositivos tecnológicos: captación técnica de lo sucedido o de lo acaecido en el espacio - implementación de dispositivos tecnológicos de largo alcance (micrófonos, aeronaves no tripuladas ${ }^{6}$, cámaras de audio y vídeo, SITEL ${ }^{7}$ ——, o inmisiones de este en remoto ${ }^{8}$.

ámbito espacial reservado, de impedir o prohibir la entrada o la permanencia en él de cualquier persona, y, específicamente, de la autoridad pública para la práctica de un registro (SSTC 189/2004, 22/2003, y 22/1984).

5 El art. 18.2 CE protege toda intervención física o a través de aparatos mecánicos, electrónicos u otros análogos (SSTC 176/2013, 10/2002, y 22/1984). El Tribunal Supremo ha señalado que la inviolabilidad del domicilio queda vulnerada por la interceptación virtual del espacio físico sin las debidas garantías (SSTS 18/2021, de 15 de enero, Sala de lo Penal, Sección 1a; 329/2016, de 20 de abril, Sala de lo Penal, Sección 1.a).

6 En lo relativo a la intervención — física o virtual — del espacio físico por aeronaves pilotadas por control remoto, la normativa reguladora de su utilización civil incluye las condiciones del vuelo en remoto con el fin de garantizar la vida e integridad física de los demás (art. 15 CE). El Real Decreto 1036/2017, de 15 de diciembre, por el que se regula la utilización civil de las aeronaves pilotadas por control remoto, y se modifican el Real Decreto 552/2014, de 27 de junio, por el que se desarrolla el Reglamento del aire y disposiciones operativas comunes para los servicios y procedimientos de navegación aérea, y el Real Decreto 57/2002, de 18 de enero, por el que se aprueba el Reglamento de Circulación Aérea, regula los requisitos que deben tener los pilotos remotos para poder manipular tales artefactos (arts. 33 a 39). También establece la necesaria autorización de la Agencia Estatal de Seguridad Aérea para la realización de las diferentes operaciones aéreas (art. 40). Sin embargo, no adiciona las garantías constitucionales para asegurar la protección del art. 18.2 CE frente a interferencias de estos artefactos en el espacio físico inviolable.

7 SITEL (sistema integrado de telecomunicaciones o sistema integral de interceptación de las comunicaciones electrónicas) constituye una aplicación informática muy avanzada que permite interceptar no solo la conversación sino también el paquete de datos que la acompaña y que se denomina «información asociada a la comunicación». Así pues, la localización geográfica del interlocutor o el tipo de contrato de los interlocutores, perteneciente al Ministerio del Interior espańol, y a lo que pueden acceder los cuerpos y fuerzas de seguridad del Estado y el CNI (https://bit.ly/3q6K4wP, acceso el 5-04-2021).

8 Así, por ejemplo, las intervenciones en remoto en las denominadas «viviendas domóticas». 
El art. 18.2 CE también asegura diferentes procedimientos de registros remotos de terminales informáticos sitos en un espacio físico para la obtención de pruebas de la presunta comisión de un delito grave (art. 588 septies a. de la LO 13/2015, de 5 de octubre, de modificación de la Ley de Enjuiciamiento Criminal para el fortalecimiento de las garantías procesales y la regulación de las medidas de investigación tecnológica; en adelante, LOMLECrim) ${ }^{9}$. Ello tanto si el registro remoto del terminal o dispositivo constitucionalmente conforme no precisa de invasión física de los manipuladores de tales artefactos (registro remoto de equipos informáticos mediante ordenador en red para la utilización de datos de identificación y códigos del terminal informático) como si tal intervención física es necesaria para la adición de un software en cualquiera de los dispositivos señalados ${ }^{10}$.

\section{DOMICILIO CONSTITUCIONALMENTE CONFORME Y DOMICILIO LEGAL}

El domicilio constitucionalmente conforme es el espacio físico inviolable. El art. 18.2 CE asegura el carácter intangible del ámbito espacial. En tal sentido, queda fuera del alcance de este derecho fundamental la pluralidad de significados que el término «domicilio» acumula en otros ámbitos del ordenamiento infraconstitucional ${ }^{11}$. La razón estriba en que los efectos jurí-

9 El art. 588 septies a. LOMLECrim permite que el juez competente pueda autorizar la utilización de datos de identificación y códigos, así como la instalación de un software, que permitan, de forma remota y telemática, el examen a distancia y sin conocimiento de su titular o usuario del contenido de un ordenador, dispositivo electrónico, sistema informático, instrumento de almacenamiento masivo de datos informáticos o base de datos, siempre que se persiga la investigación de algunos delitos graves. El denominado software espía o spyware es un programa que recopila información sobre los hábitos de navegación en la web u otras cuestiones personales de utilización del sistema del usuario sin su consentimiento. Sobre la regulación procesal del registro remoto de equipos informáticos en la LOMLECrim, Bachmaier Winter (2017: 5-11).

10 La intangibilidad del espacio físico también queda lógicamente socavada con la sola intervención física en el domicilio constitucionalmente conforme; ya sea para la aprehensión de ordenadores, instrumentos de comunicación telefónica o telemática o dispositivos de almacenamiento masivo de información digital, o para acceder a repositorios telemáticos de datos (art. 588 sexies a. LOMLECrim); también para la adición de aparatos de escucha y vídeo en él (art. 588 quáter a. LOMLECrim).

11 «El derecho fundamental a la inviolabilidad del domicilio es extensivo a las personas jurídicas [...] si bien no existe una plena correlación entre el concepto legal de domicilio de las personas jurídicas establecido por la legislación mercantil, con el del 
dicos que dimanan de tan plural regulación legal del domicilio no constituyen garantía formal de su intangibilidad.

De lo anterior se colige que el domicilio constitucionalmente conforme —el espacio físico inviolable — queda protegido por las garantías del art. 18.2 $\mathrm{CE}$ con independencia de que tal lugar sea, además, el domicilio social de una persona jurídica o «lugar donde radica el centro de la actividad, gestión o administración de una sociedad mercantil» a los efectos de notificación de los actos procesales ${ }^{12}$; o al margen de que se trate de un domicilio fiscal de la persona física o jurídica, entendiendo por tal el «lugar de localización del obligado tributario en sus relaciones con la administración tributaria» ${ }^{13}$.

domicilio constitucionalmente protegido, ya que éste es un concepto de mayor amplitud que el concepto jurídico privado o jurídico administrativo» (SSTC 54/2015, 69/1999, 50/1995, 160/1991, у 22/1984).

12 Diccionario Panispánico del Español Jurídico (RAE, 2020). Para formalizar válidamente la escritura pública de constitución los estatutos de la sociedad tienen que indicar cuál será el domicilio de la sociedad. El art. 120 RRM señala que «en los estatutos se consignará el domicilio de la sociedad, que habrá de radicar en el lugar del territorio español en que se prevea establecer el centro de su efectiva administración y dirección o su principal establecimiento o explotación».

13 Art. 48.1 LGT. Si se trata de personas físicas, la Ley General Tributaria establece que el domicilio fiscal será el lugar de su residencia habitual (art. 48.1 LGT); en el supuesto de las personas físicas que desarrollen principalmente actividades económicas en los términos que reglamentariamente se determinen, la Administración tributaria podrá considerar "como domicilio fiscal el lugar donde esté efectivamente centralizada la gestión administrativa y la dirección de las actividades desarrolladas. Si no pudiera establecerse dicho lugar, prevalecerá aquel donde radique el mayor valor del inmovilizado en el que se realicen las actividades económicas» (art. 48.2 a. LGT). Para las personas jurídicas, su domicilio fiscal se identifica con el domicilio social, «siempre que en él esté efectivamente centralizada su gestión administrativa y la dirección de sus negocios. En otro caso, se atenderá al lugar en el que se lleve a cabo dicha gestión o dirección» (art. 48.2 b. LGT). El apdo. 1 del art. 142 LGT establece cuáles son las actuaciones inspectoras y el apdo. 2 enumera los espacios susceptibles de inspección: «[...] fincas, locales de negocio y demás establecimientos o lugares en que se desarrollan actividades o explotaciones sometidas a gravamen, existan bienes sujetos a tributación, se produzcan hechos imponibles o supuestos de hecho de las obligaciones tributarias o exista alguna prueba de los mismos». Asimismo, el art. 142.2 in fine LGT diferencia entre espacios físicos constitucionalmente conformes (art. 113 LGT) y los que no lo son al efecto de exigir autorización judicial - $-\mathrm{y}$ no administrativa - para entrar y registrar tales espacios siempre que no exista consentimiento informado del obligado tributario.

El Tribunal Constitucional no solo ha identificado el domicilio constitucional de las personas jurídicas con el domicilio social; también con aquellos espacios físicos 
El espacio físico inviolable tampoco se identifica con el domicilio civil que supone el lugar de residencia habitual para el ejercicio de los derechos y el cumplimiento de las obligaciones civiles de la persona física o jurídica ${ }^{14}$; o con el domicilio protegido frente a su entrada para la ejecución forzosa de los actos de la Administración, que la doctrina identifica con el lugar para el presumible o efectivo desarrollo de la vida íntima o privada, diferenciándolo de los «restantes edificios o lugares cuyo acceso requiera el consentimiento del titular» ex art. 91.2 LOPJ $^{15}$.

pertenecientes a la persona jurídico-privada en los que sea indispensable el ejercicio de su actividad sin intromisiones ajenas por tratarse de establecimientos dependientes, o por existir documentos o datos reservados al conocimiento de terceros (STC 54/2015). En suma, identificando el espacio físico con la verificación de la existencia de vida privada en él pero no con su carácter inviolable.

14 El primer inciso del art. $40 \mathrm{CC}$ identifica el domicilio civil de las personas naturales con «el lugar de su residencia habitual, y, en su caso, el que determine la Ley de Enjuiciamiento Civil». Para los diplomáticos residentes por razón de su cargo en el extranjero, que gocen del derecho de extraterritorialidad, el art. 40 in fine determina que el domicilio será "el último que hubieren tenido en territorio español» (art. 40 CC). En relación con las personas jurídicas, el art. 41 CC prevé que «cuando ni la ley que las haya creado o reconocido, ni los estatutos o las reglas de fundación» hayan fijado su domicilio, se entenderá que lo tienen «en el lugar en que se halle establecida su representación legal, o donde ejerzan las principales funciones de su instituto». La distinción entre el domicilio civil y el espacio físico inviolable se ha puesto de manifiesto en la jurisprudencia del Tribunal Constitucional en relación con la notificación de los actos procesales en el domicilio en el que el individuo reside habitualmente. Tal notificación tiene como fin proteger la correcta ejecución de los actos de comunicación procesal, de conformidad con el art. 24.1 CE. Sin embargo, no tiene por objeto proteger la inviolabilidad del espacio físico, ex art. 18.2 CE: «En este sentido hemos declarado que, cuando del examen de los autos o de la documentación aportada por las partes se deduzca la existencia de un domicilio que haga factible practicar de forma personal los actos de comunicación procesal con el demandado, debe intentarse esta forma de notificación antes de acudir a la notificación por edictos» (STC 167/2015); sobre la limitación de la comunicación de los actos procesales mediante edictos, véanse las SSTC 137/2017, 106/2017, 6/2017, 5/2017, 200/2016, 151/2016, 150/2016, 181/2015, y 89/2015, entre otras.

15 La doctrina ha señalado que el «domicilio» quedaría protegido por el art. 18.2 CE por considerar que tal espacio se identifica con el lugar en el que se presume el desarrollo de la vida íntima o privada o se verifica la efectiva existencia de tal tipo de existencia vital en él, mientras que los restantes lugares que requieran el consentimiento de su titular quedarían protegidos por las garantías del art. 33 CE (López Menudo, 2009: 5-44). 
En el mismo sentido, el espacio físico inviolable no se equipara al domicilio de las personas jurídicas públicas y privadas, pues lo asegurado es la intangibilidad del espacio y no su título de pertenencia. Tampoco se identifica con otros espacios físicos - morada, establecimiento público en horario de cierre, despachos y oficinas - que el Código Penal menciona para tipificar como delito su intervención por parte de terceros - particulares o funcionarios públicos- sin el consentimiento del titular ${ }^{16}$.

Sin embargo, se observa que la normativa administrativa precisa de una misma autorización judicial de entrada tanto para los «domicilios» como para los «restantes edificios o lugares cuyo acceso requiera el consentimiento de su titular» (art. 91.2 LOPJ): «[...] corresponde también a los Juzgados de lo Contencioso-administrativo autorizar, mediante auto, la entrada en los domicilios y en los restantes edificios o lugares cuyo acceso requiera el consentimiento de su titular, cuando ello proceda para la ejecución forzosa de actos de la Administración, salvo que se trate de la ejecución de medidas de protección de menores acordadas por la Entidad Pública competente en la materia». Asimismo, el art. 100.3 de la Ley 39/2015, de 1 de octubre, del Procedimiento Administrativo Común y de las Administraciones Públicas, señala que cuando «fuese necesario entrar en el domicilio del afectado o en los restantes lugares que requieran la autorización de su titular, las Administraciones Públicas deberán obtener el consentimiento del mismo o, en su defecto, la oportuna autorización judicial». El Tribunal Supremo ha seńalado que «la necesidad de autorización judicial para que la Administración pública pueda entrar en un inmueble para ejecutar forzosamente una previa actuación administrativa [...] constituye una excepción constitucional y legal al principio de autotutela administrativa reconocido por nuestro ordenamiento jurídico en favor de las administraciones públicas por razón de la necesaria efectividad del derecho subjetivo a la inviolabilidad domiciliaria consagrado tanto en el orden constitucional como en el internacional» (STS 1343/2019, de 10 de octubre, Sala de lo Contencioso-Administrativo, Sección 2.a).

16 Bajo la rúbrica «Del allanamiento de morada, domicilio de personas jurídicas y establecimientos abiertos al público», el capítulo II del título X utiliza el término «morada» de las personas físicas, que se identifica con el «espacio cerrado y separado del mundo exterior en el que se desarrolla la vida privada, destinado a pernoctar y en uso actual, aunque no necesariamente permanente» (RAE, Diccionario Panispánico del Español Jurídico, 2020); también se alude al domicilio atributivo de las personas jurídicas (privadas o públicas), y se incluyen otros espacios físicos (despachos y oficinas, o establecimientos abiertos al público en horario de cierre), para proscribir su allanamiento contra la voluntad de su titular por persona física o funcionario público. El art. 202.1 CP castiga al particular que, sin habitar en ella, entre en morada ajena o se mantenga en esta contra la voluntad de su morador. Asimismo, el art. $203 \mathrm{CP}$ castiga al que entre contra la voluntad de su titular en el «domicilio de una persona jurídica pública o privada, despacho profesional u oficina, o en establecimiento mercantil o local abierto al público fuera de las horas de apertura». Este delito se castiga también si es cometido por funcionario público (art. 204 CP). 
El domicilio protegido penalmente ni siquiera es coincidente con la enumeración de los espacios físicos así calificados en el art. 554 LECrim para la ejecución procesal-penal de las garantías de la limitación del art. 18.2 CE; una regulación que está basada en la identificación del espacio físico con el presumible o efectivo desarrollo de la vida íntima o privada en él más que con su carácter inviolable: palacios reales, estén o no habitados por el monarca al tiempo de la entrada o registro; edificio o lugar cerrado, o la parte destinada principalmente a la habitación de cualquier español o extranjero residente en España y de su familia; buques nacionales mercantes, y espacios físicos que constituyan el centro de dirección de las personas jurídicas, ya se trate de su domicilio social o de un establecimiento dependiente, o aquellos otros lugares en que se custodien documentos u otros soportes de su vida diaria que quedan reservados al conocimiento de terceros. La inviolabilidad del espacio físico también impide diferenciar entre «cualquier edificio o lugar cerrado o parte de él, que constituya domicilio de cualquier español o extranjero residente en España» (art. 550 LECrim) y el espacio físico "no domiciliar» al efecto de proteger, únicamente, la entrada del primero.

\section{UN DERECHO FUNDAMENTAL AUTÓNOMO}

El art. 18.2 CE constituye un derecho fundamental autónomo; asegura la inviolabilidad del espacio físico pero no garantiza el poder de disposición de este por quien es titular legítimo - propietario o poseedor- (art. $33 \mathrm{CE}$ ). Tampoco protege la libertad personal en el espacio físico (art. $17 \mathrm{CE}$ ) o el libre desarrollo de la personalidad en él (art. 10.1 CE).

\section{INVIOLABILIDAD DEL DOMICILIO Y DERECHO A LA PROPIEDAD (ART. 33.1 CE)}

El art. 18.2 CE asegura la inviolabilidad del espacio físico pero no garantiza el poder de disposición de este por quien es su titular legítimo - propietario o poseedor- (art. $33 \mathrm{CE})^{17}$. Constituye un derecho diferente al de

17 El Tribunal Constitucional ha señalado que el art. 18.2 CE no puede confundirse con la protección de la propiedad de los inmuebles ni de otras titularidades reales u obligacionales relativas a dichos bienes que puedan otorgar una facultad de exclusión de los terceros (SSTC 32/2019, 10/2002, 69/1999, 149/1991, y 76/1992; y AATC 333/1993, 223/1993, 58/1992, 198/1991, 171/1989, 349/1988, у 272/1985). 
propiedad $^{18}$, pues no protege frente a actuaciones que dificultan o impiden la libre disposición del espacio físico por su titular o poseedor legítimo ${ }^{19}$. En este

En reiterada jurisprudencia, el Tribunal Constitucional ha señalado que el derecho a la propiedad privada queda limitado mediante dos formas de intervención del poder público en la propiedad de intensidad diversa (apdos. 2 y 3 del art. $33 \mathrm{CE}$ ): la imposición de límites, obligaciones o cargas derivadas de la función social de los derechos patrimoniales, por un lado (apdo. 2 del art. $33 \mathrm{CE}$ ), y la privación de esos derechos, por otro (apdo. 3 del art. $33 \mathrm{CE}$ ). Las limitaciones, cargas u obligaciones impuestas por el legislador ex art. 33.2 CE no pueden suponer la desaparición o negación del contenido esencial del derecho ni la delimitación del derecho puede carecer de fundamento o justificación constitucional. Por tanto, se establecen dos límites que debe respetar el legislador al delimitar las situaciones patrimoniales subjetivas conforme a las exigencias de su función social: el contenido previo e indisponible del derecho fundamental (art. 53.1 CE) y el principio de proporcionalidad. El art. 33.3 CE, por su parte, regula las garantías constitucionales de la expropiación forzosa, que se imponen a todos los poderes públicos, tanto a la Administración cuando acuerda la expropiación administrativa como al legislador cuando, en casos excepcionales, acuerda una expropiación legislativa permitida por la Constitución. La expropiación forzosa requiere que la privación imperativa que esta comporta tenga su causa en un motivo de utilidad pública o interés social, lo que no solo constituye una garantía de la expropiación, sino también un elemento de su definición, pues constituye el fin público que justifica la medida expropiatoria. Así pues, el Tribunal Constitucional prohíbe toda expropiación arbitraria o discrecional, pues en todos los supuestos han de motivarse las razones que la justifican (SSTC 116/2019, 43/2018, 48/2005, y 37/1987). Sobre el objeto protegido y las garantías de la delimitación restrictiva del art. 33 CE, véase la siguiente doctrina: Rey Martínez (2011: 279-286) y Rodríguez de Santiago (2018: 1154-1172).

18 El primer constitucionalismo histórico español identificó la inviolabilidad del domicilio (la prohibición de allanamiento de «la casa» ex art. 306 de la Constitución de 1812) y el derecho de propiedad (art. 4) como derechos autónomos. En el mismo sentido se muestra la Constitución de 1837, que regula, de nuevo, la prohibición de allanamiento de la casa y el derecho de propiedad en los arts. 7 y 10 , respectivamente. Sin embargo, en la medida en que se utiliza el término "casa» para regular la prohibición de allanamiento, el poder constituyente de 1837 expresa que la finalidad del art. 7 es garantizar la «inviolabilidad de su propiedad» (DSCC, 24 de febrero de 1837). Sobre el análisis del iter constituyente del art. 7 de la Constitución de 1837, véase Pascual López (2001: 126-132). Como ha seńalado la doctrina, el art. 18.2 CE puede ser vulnerado «sin que, por ello, se ponga en peligro necesariamente la propiedad del bien» (Matia Portilla, 1997: 15).

19 En reciente jurisprudencia (STC 32/2019), el Tribunal Constitucional ha señalado que los procedimientos habilitados para los desalojos de personas originados por demandas de presumibles propietarios (art. $33 \mathrm{CE}$ ) no constituyen una vulneración de la 
sentido, se vulneran ambos derechos cuando los ocupantes ilegítimos del espacio físico no solo han entrado en él sin las debidas garantías, sino que también han obstaculizado el poder de disposición del poseedor legítimo del espacio. Se socava igualmente la inviolabilidad del espacio físico del presunto detentador ilegítimo si dicha intervención para su desalojo y posterior recuperación de la posesión no se realiza con las debidas garantías ${ }^{20}$. Ello supone que la solicitud de autorización judicial para proceder a su desalojo deberá ir precedida de la correspondiente acreditación del título jurídico habilitante de su detentador legítimo ${ }^{21}$.

\section{INVIOLABILIDAD DEL DOMICILIO Y LIBERTAD PERSONAL (ART. 17.1 CE)}

El art. 18.2 CE tampoco garantiza la «libertad del domicilio», o la libertad personal en el domicilio, expresión que el Tribunal Constitucional ha utilizado en alguna ocasión ${ }^{22}$.

inviolabilidad del espacio domiciliar de los desahuciados si tal intervención se realiza con las debidas garantías (autorización judicial): «La decisión judicial de proceder al desalojo de los ocupantes que puede adoptarse en el proceso sumario para la recuperación de la posesión de la vivienda instituido por la Ley 5/2018, si aquellos no hubieran justificado suficientemente su situación posesoria y siempre que el título que el actor hubiere acompañado a la demanda fuere bastante para acreditar su derecho a poseer, no constituye una violación del derecho a la inviolabilidad del domicilio garantizado por el art. 18.2 CE». Asimismo, el Tribunal Europeo de Derechos Humanos (STEDH de 13 de diciembre de 2018, asunto Casa di Cura Valle Fiorita, S.R.L. c. Italia) ha reconocido, recientemente, que la demora prolongada de las autoridades públicas a la hora de ejecutar una orden judicial de desalojo de los ocupantes ilegales de un inmueble, aun escudándose en la necesidad de planificar cuidadosamente el desalojo con el fin de preservar el orden público y garantizar la asistencia a las personas en situación de vulnerabilidad que participaron en la ocupación, vulnera el derecho del titular legítimo a un proceso equitativo que garantiza el art. 6.1 del Convenio Europeo de Derechos Humanos (CEDH), así como su derecho de propiedad (art. 1 del protocolo n. ${ }^{0} 1 \mathrm{CEDH}$ ).

20 En este sentido, el Tribunal Constitucional ha señalado que el desalojo de una habitación de una residencia militar mediante autorización administrativa por incumplimiento de las normas de régimen interior de la residencia de su detentador ilegítimo (impago de habitación) vulnera el derecho a la inviolabilidad del domicilio de este, en la medida en que tal intervención precisó de autorización judicial (STC 189/2004).

21 STC 32/2019.

22 «En suma, la libertad del domicilio se califica como reflejo directo de la protección acordada en el ordenamiento a la persona» (STC 137/1985). Por primera vez, la 
En puridad, el art. 18.2 CE no opera como derecho instrumental de la libertad personal en el domicilio, pues lo protegido es la intangibilidad del espacio físico; no, así, «la plena autodeterminación del propio movimiento corporal $»^{23}$, o la "capacidad o libertad de orientar la propia acción $»^{24}$ frente a privaciones de la libertad arbitrarias, aunque tales detenciones legal o constitucionalmente disconformes tengan lugar como consecuencia de la entrada en el espacio inviolable.

La privación de libertad sin las debidas garantías queda protegida, en su caso, por la libertad personal de conformidad con el art. 17.1 CE y la correspondiente legislación reguladora (Lascuraín Sánchez, 2018: 447-448). De tal forma que la detención policial de un individuo — la limitación de la libertad

Constitución de 1837 regula en el mismo precepto (art. 7) tanto la prohibición de allanar la casa como la prohibición de ser detenido, preso o separado de su domicilio: «[...] no puede ser detenido ni preso, ni separado de su domicilio ningún español, ni allanada su casa, sino en los casos y en la forma que las leyes prescriban». La doctrina ha considerado que tal regulación que se reitera en la Constitución de 1845 supone "la directa vinculación del derecho a la inviolabilidad del domicilio con la libertad personal», pues, «además de recogerse la defensa frente al allanamiento de la casa, se amplía la garantía a la prohibición de apresar; detener y separar» (González Trevijano, 1992: 96-97). Sin embargo, la Constitución de 1869 regula de forma separada la inviolabilidad del «domicilio» («Nadie podrá entrar en el domicilio de un español, o extranjero residente en Espańa, sin su consentimiento, excepto en los casos urgentes de incendio, inundación u otro peligro análogo, o de agresión ilegítima procedente de dentro, o para auxiliar a persona que desde allí pida socorro», art. 5), la libertad personal («Ningún español ni extranjero podrá ser detenido ni preso sino por causa de delito». "Todo detenido será puesto en libertad o entregado a la Autoridad judicial dentro de las veinticuatro horas siguientes al acto de la detención. Toda detención se dejará sin efecto o elevará a prisión dentro de las setenta y dos horas de haber sido entregado el detenido al juez competente. La providencia que se dictare se notificará al interesado dentro del mismo plazo», arts. 2 y 3), y la libertad de residencia («Ningún español puede ser compelido a mudar de domicilio o de residencia sino en virtud de sentencia ejecutoria", art. 6).

23 STC 23/1985.

24 STC 341/1993. El Tribunal Constitucional ha señalado que en un Estado democrático en el que los derechos fundamentales quedan protegidos de modo real y efectivo, la libertad de los ciudadanos es la regla general y no la excepción, de modo que los individuos gozan de autonomía para elegir entre las diferentes opciones vitales que se les presentan. Asimismo, tal libertad personal queda delimitada, de modo restrictivo por lo establecido en el art. $17 \mathrm{CE}$ y lo que establezcan las leyes, pues constituye el derecho de todos a no ser privados de esta, salvo «en los casos y en la forma previstos por la Ley» (STC 29/2008). 
personal- requiere garantías diferentes (arts. 17 CE y 520 LECrim) a las que limitan el derecho del art. 18.2 CE cuando los agentes precisan la entrada en el espacio físico para proceder a la detención de un individuo y posterior puesta a disposición judicial ${ }^{25}$.

\section{INVIOLABILIDAD DEL DOMICILIO Y LIBRE DESARROLLO DE LA PERSONALIDAD (ART. 10.1 CE)}

En parecido sentido, se puede afirmar que el art. 18.2 CE alcanza la inviolabilidad del espacio físico pero no asegura el libre desarrollo de la personalidad en él; tampoco protege el libre desarrollo de la vida privada del poseedor del espacio físico, como ha señalado el Tribunal Constitucional en su jurisprudencia a partir de la primera década del siglo $\mathrm{XXI}^{26}$. Todo ello al paso de una abundante jurisprudencia del Tribunal Europeo de Derechos Humanos que desarrolla una dimensión positiva del derecho fundamental (la obligación de los poderes públicos de garantizar el efectivo disfrute de la vida privada domiciliar) disconforme con el enunciado del derecho fundamental. Por las mismas razones, tampoco puede aceptarse, siquiera, que el libre desarrollo de la personalidad del comorador precario que consiente la entrada de tercero constituya el contenido inesencial de un derecho que se subordina a la facultad de exclusión de terceros de cualquiera de los detentadores del espacio físico (contenido esencial de este) ${ }^{27}$.

25 STC 209/2007.

26 «Teniendo esto presente, podemos concluir que una exposición prolongada a unos determinados niveles de ruido, que puedan objetivamente calificarse como evitables e insoportables, ha de merecer la protección dispensada al derecho fundamental a la intimidad personal y familiar, en el ámbito domiciliario, en la medida en que impidan o dificulten gravemente el libre desarrollo de la personalidad, siempre y cuando la lesión o menoscabo provenga de actos u omisiones de entes públicos a los que sea imputable la lesión producida» (STC 119/2001). En el mismo sentido, véanse las SSTC 150/2011 y 16/2004, y la STS 436/2001, de 19 de marzo (Sala de lo Penal, Sección 1.a).

27 «Si la convivencia en un mismo domicilio no altera, en principio, ni la titularidad del derecho ni la posibilidad de su ejercicio, resulta que cada titular del mismo mantiene una facultad de exclusión de terceros del espacio domiciliario que se impone al ejercicio del libre desarrollo de la personalidad del comorador que desea la visita de un tercero que no mora en él. Ello no obsta para que la composición razonable de los intereses en juego de los comoradores haga que usualmente pacten explícita o implícitamente la tolerancia de las entradas ajenas consentidas por otro comorador y que 
El libre desarrollo de la personalidad constituye un principio orientador de la actuación de los poderes públicos (art. 10.1 CE). En la medida en que está contemplado en la Constitución, los poderes públicos, y en particular el juez, deben orientar su labor al respeto al principio del libre desarrollo de la personalidad (De Otto y Pardo, 1995: 85); sin embargo, tal reconocimiento de la libertad genérica lo es en el respeto de la ley y de los derechos fundamentales y libertades públicas «al margen de los cuales la Constitución ya no preservaría la autonomía del sujeto sino la del legislador democrático $»^{28}$.

Los nuevos procesos productivos especialmente dañinos en términos medioambientales han estimulado una novedosa jurisprudencia del Tribunal Constitucional injertando una dimensión positiva en este derecho fundamental que dilata el objeto protegido por el art. 18.2 CE más allá de lo que su enunciado reconoce.

Bajo la rúbrica «Derecho al respecto a la vida privada y familiar», el parágrafo $1 .^{\circ}$ del art. $8 \mathrm{CEDH}$ reconoce el derecho «al respeto de su vida privada y familiar, de su domicilio y de su correspondencia». Aunque la Constitución española dota de entidad propia a los derechos fundamentales a la intimidad personal y familiar (art. 18.1 CE), y a la inviolabilidad del domicilio (art. 18.2 $\mathrm{CE})$, la jurisprudencia del TEDH ha reconocido que el respeto del domicilio - como el secreto de la correspondencia - es un derecho instrumental del derecho a la vida privada y familiar por incluirse bajo la denominación genérica que aparece en la rúbrica del art. $8 \mathrm{CEDH}^{29}$.

los terceros que ingresen en el domicilio puedan así confiar a priori en que la autorización de uno de los titulares del domicilio comporta la de los demás» (STC 209/2007). En el mismo sentido, véase la STC 22/2003.

28 "Este proclamado "libre desarrollo de la personalidad" no puede ser concebido, en consecuencia, como una fuente de legitimación del propio arbitrio, al margen del Derecho» (Jiménez Campo, 2018: 223).

29 Asimismo, el Tribunal Europeo de Derechos Humanos ha reconocido que la expresión "vida privada» domiciliar tiene un significado amplio extensivo de la vida privada «social» que se proyecta en las interacciones que el individuo mantiene con los demás (STEDH de 16 de diciembre de 1992, asunto Niemietz c. Alemania; STEDH de 23 de marzo de 2006, asunto Campagnano c. Italia, STEDH de 28 de mayo de 2009, asunto Bigaeva c. Grecia, STEDH de 18 de enero de 2018, asunto Federación Nacional de Asociaciones y Sindicatos Deportivos c. Francia). Como ha señalado Elvira Perales, el art. 10.2 CE impone interpretar los derechos a la luz de los tratados y acuerdos internacionales, y — por extensión- de los tribunales que los interpretan, pero «no ha de ser la vía para crear nuevos derechos fundamentales, sin perjuicio de que, en determinados supuestos, esos tratados puedan servir para cubrir la regulación de un derecho, de acuerdo con lo ya expuesto» (2019: 169). También ha 
La citada problemática medioambiental ha generado, sin embargo, una jurisprudencia del TEDH que añade un nuevo sentido al respeto del domicilio que no está contenido en el enunciado del art. 8.1 CEDH: el derecho al «disfrute» $\mathbf{o}$ «goce» de la vida privada domiciliar ${ }^{30}$. Se afirma que el respeto al domicilio no solo protege el espacio físico frente a intervenciones ajenas; también obliga a los poderes públicos a dotar de efectividad el derecho al disfrute o goce de dicho espacio "con tranquilidad" ${ }^{31}$.

El Tribunal Constitucional reconoce que, a diferencia del art. 8.1 $\mathrm{CEDH}$, el art. $18 \mathrm{CE}$ dota de entidad propia a los derechos fundamentales a la intimidad personal y familiar (art. 18.1 CE) y a la inviolabilidad del domicilio (art. 18.2 CE). Sin embargo, vincula la exposición prolongada a procesos ambientales nocivos con la necesidad de actuar para proteger el libre desarrollo de la vida privada en el espacio ${ }^{32}$.

Verdaderamente, el art. 18.2 CE no asegura el goce de la vida privada domiciliar, que es conforme con el libre desarrollo de la personalidad, ni el derecho a disfrutar del espacio con tranquilidad ${ }^{33}$. En puridad, la inacción de los poderes públicos en relación con los elevados niveles de saturación acústica o de olores vulnera otro derecho fundamental distinto al de la inviolabilidad del espacio domiciliar: la integridad física y moral del individuo (art. $15 \mathrm{CE}$ ).

En suma, los daños medioambientales provocados por una exposición prolongada a elevados niveles de saturación acústica, gases u olores que pongan en peligro la salud de los ciudadanos con la inacción u omisión de los poderes públicos no vulneran la inviolabilidad del domicilio ni el libre desarrollo de la vida privada domiciliar. Tampoco conculcan el derecho al goce o disfrute del domicilio con tranquilidad; vulneran, en realidad, la incolumidad corporal

señalado que la acomodación de varios derechos en el mismo art. $8 \mathrm{CEDH}$ no presenta «las diferencias que afloran en nuestro texto constitucional» (Elvira Perales, 2020: 125).

30 SSTEDH de 16 de noviembre de 2004, asunto Moreno Gómez contra España; de 19 de febrero de 1998, asunto Guerra y otros c. España; de 9 de diciembre de 1994 , asunto López Ostra c. España, y de 21 de febrero de 1990, asunto Powell y Rayner c. Reino Unido.

31 STEDH de 3 de julio de 2012, asunto Martínez Martínez y Pino Manzano c. España; en el mismo sentido, STEDH de 6 de septiembre de 2005, asunto Ruano Morcuende c. España.

32 SSTC 150/2011, 16/2004 y 119/2001.

33 Estas reflexiones no son obstáculo para que los poderes públicos lleven a cabo las medidas necesarias orientadas a perseguir el disfrute de un medio ambiente sano por parte de la ciudadanía (art. $45 \mathrm{CE}$ ) en cuanto tal exigencia de principio se orienta a proteger la salud de los ciudadanos (art. $43 \mathrm{CE}$ ). 
—física o moral- (Aguado Renedo, 2011: 140-141 y 145-146), objeto protegido por el derecho fundamental a la integridad física y moral (art. $15 \mathrm{CE})^{34}$.

\section{NATURALEZA FORMAL}

El art. 18.2 CE asegura la inviolabilidad del espacio físico, al margen de cuál sea su previsible o efectivo destino, o de que nada transcurra o se contenga en él ${ }^{35}$. No constituye un derecho instrumental del derecho a la intimidad personal y familiar (art. 18.1 CE), pues queda vulnerado con la sola intervención sin las debidas garantías ${ }^{36}$. La inviolabilidad del espacio físico no se

34 En este sentido, el derecho a que no se dañe o perjudique la salud personal queda comprendido en el derecho a la integridad personal; sin embargo, no todo supuesto de riesgo o daño para la salud debe implicar una vulneración del derecho fundamental a la integridad personal, sino tan solo aquel que genere un peligro grave y cierto para esta (SSTC 118/2019, 160/2007, 62/2007, 5/2002, 119/2001, y 35/1996). La doctrina ha afirmado que no cualquier riesgo o amenaza constituye, sin más, una vulneración del derecho fundamental. Sin embargo el Tribunal Constitucional presenta ciertas imprecisiones en relación con la intensidad que debe revestir dicho riesgo o amenaza para que pueda estimarse efectivamente lesivo: «Si las SSTC 35/1996 y 221/2002 hablan, respectivamente, de la existencia de "riesgo para la salud" o de un "riesgo relevante", existe otro grupo de sentencias que exigen que se trate de "grave riesgo", "peligro grave e inmediato", "peligro grave y cierto", "riesgo palmario y manifiesto" o "riesgo constatado de producción cierta, o potencial pero justificado ad casum [...] riesgo o peligro grave”, SSTC 7/1994, 119/2001, 5/2002, 220/2005 y 62/2007, respectivamente» (Arruego Rodríguez, 2008: 62). Sobre la relación entre el derecho a la integridad personal y la salud, véase Pérez Manzano y Tomás-Valiente Lanuza (2018: 383-385).

35 Ya se trate de acontecimientos más o menos íntimos protagonizados por los detentadores del espacio, o de actuaciones que tienen lugar sin que los poseedores del espacio se encuentren en él (el ruido de un grifo mal cerrado, una radio encendida, el sonido de un lavavajillas en funcionamiento, o el de los aparatos de una vivienda domótica controlados en remoto).

36 Ciertamente, hasta 1869, el constitucionalismo histórico español identificó el espacio físico susceptible de prohibición de allanamiento con la "casa» (art. 306 de la Constitución de 1812, art. 7 de la Constitución de 1837, y art. 7 de la Constitución de 1845), lo que redundó, a posteriori, en una identificación del «domicilio» impenetrable (art. 5 de la Constitución de 1869 y art. 6 de la Constitución de 1876) con el espacio físico para el desarrollo de la vida familiar. En los debates constituyentes para la aprobación del art. 5 de la Constitución de 1869, Figueras identifica la «inviolabilidad del domicilio» con el reconocimiento del derecho de la familia: "Al reconocer el derecho de la familia era consecuencia indispensable que reconocierais la inviolabilidad del 
presume; describe el estado del espacio, en función de los identificadores asociados a él, de tal forma que un mismo espacio puede ser inviolable o no condicionado por elementos factuales de carácter temporal.

El Tribunal Constitucional identificó, inicialmente, el domicilio constitucionalmente conforme con su presumible o efectivo destino: servir al desarrollo de la «libertad más íntima $»^{37}$, o la «vida privada $»^{38}$. En un primer momento, por advertirse la existencia de actividades o de bienes muebles identificativos del desarrollo de vida íntima o privada tras la intervención del espacio físico ${ }^{39}$; con posterioridad, por presumir que la configuración física del espacio —una vivienda - o el edificio que lo contiene determinan el destino ${ }^{40}$. Ello con independencia de su naturaleza — mueble o inmueble —, temporalidad de uso, o título jurídico que lo habilite ${ }^{41}$, o al margen de que se encuentre deshabitado ${ }^{42}$.

domicilio» (DSCC, 6 de abril de 1869). Moret identifica el domicilio con las «cuatro paredes de nuestra casa» (DSCC, 8 de abril de 1869). Y Romero Girón considera al domicilio como la «manifestación de un derecho en sus más altas relaciones, en las relaciones de la familia» (DSCC, 16 de abril de 1869). Asimismo, el art. 31 in fine de la Constitución de 1931 identifica el domicilio con la vivienda al establecer que el domicilio inviolable queda delimitado restrictivamente a la posibilidad de intervenirlo y registrarlo mediante mandato judicial y con la presencia del interesado, de una persona de su familia, o, en su defecto, de dos vecinos del mismo pueblo, en el mismo sentido regulado en las Constituciones de 1869 y 1876 (Pascual López, 2001: 122-162). En tal sentido, el «domicilio inviolable» es el espacio en el cual el individuo «vive sin estar sujeto necesariamente a los usos y convenciones sociales y ejerce su libertad más íntima». Por ello, lo protegido no es solo el espacio físico en sí mismo considerado, sino lo que en él hay de emanación de la persona y de su esfera privada (SSTC 81/2020, 32/2019, 54/2015, 188/2013, 176/2013, 150/2011, 106/2012, 209/2007, 119/2001, 94/1999, 69/1999, 50/1995, 160/1991, 228/1987, 137/1985, y 22/1984). La misma jurisprudencia ha utilizado el término «ámbito espacial íntimo» (SSTC 209/2007 y 22/2003).

38 "[...] este Tribunal ha ido perfilando una noción de domicilio de la persona física cuyo rasgo esencial reside en constituir un ámbito espacial apto para un destino específico, el desarrollo de la vida privada» (STC 10/2002). En el mismo sentido, SSTC 32/2019, 54/2015, 209/2007, 283/2000, 94/1999, 137/1985, y 22/1984. Sobre el desarrollo en este sentido de la jurisprudencia del TC, véase Navas Sánchez (2011: 162-168).

39 STC 22/1984.

40 SSTC 209/2007, 10/2002, 89/2004, y 94/1999.

41 SSTC 209/2007 y 10/2002. También con independencia de que no se sea propietario del espacio físico, pero se sepa que lo ocupa habitualmente (STS 272/2017, de 18 de abril, Sala de lo Penal, Sección 1.a).

42 SSTC 10/2002 y 94/1999. En las personas jurídico-privadas, la vida privada se presume en los espacios indispensables para «desarrollar su actividad sin intromisiones ajenas por constituir el centro de dirección de la sociedad o de un 
En ocasiones, ha identificado el domicilio constitucionalmente conforme con el «ámbito de privacidad ${ }^{43}$, la «garantía formal de su intangibilidad ${ }^{44}$, o el espacio para la realización de «alguna actividad» ${ }^{45}$. Lo que finalmente ha afectado al rigor de su carácter de garantía formal al introducirse en el análisis su destino presumible o efectivo ${ }^{46}$.

La identificación del espacio físico protegido con la finalidad propia de su función domiciliaria supone, a mi juicio, una limitación del objeto del derecho al asegurar solo algunos espacios «inviolables»: aquellos en los que se presume o evidencia el desarrollo de vida íntima (en sentido originario) ${ }^{47} \mathrm{o}$ "privada», conforme al enunciado amplio que se contiene en el art. $8 \mathrm{CEDH}^{48}$.

establecimiento dependiente de la misma»; o se constata en la existencia de «documentos u otros soportes de la vida diaria de la sociedad o de su establecimiento que quedan reservados al conocimiento de terceros» (SSTC 54/2015 y 69/1999). SSTC 176/2013, 10/2002, 137/1985, y 22/1984. De conformidad con la jurisprudencia del Tribunal Constitucional, el Tribunal Supremo ha establecido que un trastero sin comunicación directa con la vivienda no es un domicilio porque no constituye un «ámbito de privacidad» (STS 279/2013, de 6 de marzo, Sala de lo Penal, Sección 1.a). STC $176 / 2013$.

45 STC 106/2012. El Tribunal Supremo señala que, en sentido constitucional, el domicilio «no sólo es lugar donde se pernocta habitualmente o donde se realizan otras actividades cotidianas habituales, sino también el ámbito cerrado erigido por una persona con objeto de desarrollar en él alguna actividad» (STS 436/2001, de 19 de marzo, Sala de lo Penal). Se pretende, así, que «el concepto subyacente en el artículo 18.2 CE se entienda de modo amplio y flexible ya que trata de defender los ámbitos en los que se desarrolla la vida privada de las personas» (STS 113/2018, de 12 de marzo, Sala de lo Penal, Sección 1.a).

46 Privacidad del ámbito - y no desarrollo de vida privada en él— que debe distinguirse de la privacy o derecho a la privacidad como derecho de las personas a controlar la información sobre la vida privada proveniente de los medios de información, que surge en el derecho norteamericano a partir del siglo xix y que suele atribuirse al clásico trabajo de Samuel D. Warren y Louis D. Brandeis The right to privacy. El derecho a la privacidad (the right to privacy) otorga protección al individuo frente al conocimiento de los datos de su vida privada por terceros a través de las nuevas tecnologías del momento (la fotografía). En este sentido, el derecho a la privacidad constituye «la exigencia espiritual o psicológica de toda persona de controlar su esfera privada y su propia información personal» en la medida en que el conocimiento de tal información menoscaba «su integridad psicológica», o el «núcleo de la personalidad individual» (Saldaña, 2012: 212-213).

47 STC 69/1999.

48 Bajo la denominación «derecho al respeto a la vida privada y familiar», el art. 8 reconoce en su apdo. $1 .^{\circ}$ el derecho de toda persona al «respeto de su vida privada y familiar, 
Esta identificación entre «vida íntima» $\mathrm{y}$ «vida privada» no ha sido aceptada por un sector de la doctrina, que defiende la disimilitud de enunciados de los arts. 18.1 CE y 8.1 $\mathrm{CEDH}^{49}$. Sin embargo, se ha visto favorecida, a

de su domicilio y de su correspondencia». El Tribunal Europeo de Derechos Humanos señala que la vida privada no incluye solo una noción restringida — la vida íntima-, sino una vertiente social — la vida privada social—, que alcanza el carácter confidencial de las interacciones que el individuo mantiene con los demás —actividades comerciales y profesionales de carácter confidencial- En tal sentido, valora ad casum si el espacio intervenido es un domicilio porque se presume y se verifica intimidad o vida privada social de carácter confidencial en él (SSTEDH de 8 de diciembre de 2020, asunto Bostan c. República de Moldavia; de 18 de enero de 2018, asunto Federación Nacional de Asociaciones y Sindicatos Deportivos c. Francia; de 28 de mayo de 2009, asunto Bigaeva c. Grecia; de 22 de mayo de 2008, asunto Ililla Stelanor c. Bulgaria; de 13 de marzo de 2007, asunto Castravet contra Moldavia; de 23 de marzo de 2006, asunto Campagnano c. Italia, y de 16 de diciembre de 1992, asunto Niemietz c. Alemania. La jurisprudencia del Tribunal Constitucional no siempre ha sido coincidente en la consideración de que el art. 18.1 CE protege también la vida privada de conformidad con la jurisprudencia del Tribunal Europeo de Derechos Humanos (SSTC 186/2013, 60/2010 y 236/2007). En este sentido, es relevante el voto particular a la STC 11/2016 de la magistrada Encarnación Roca Trías. En él señala que la interpretación de los derechos fundamentales de conformidad con los tratados internacionales (art. 10.2 CE) no significa que se puedan identificar dos enunciados normativos disímiles: «En realidad se equipara el art. 18.1 CE a lo dispuesto en el art. $8 \mathrm{CEDH}$, olvidando que lo que el art. 10.2 CE establece es la obligación de la interpretación de los derechos fundamentales de conformidad con los Tratados Internacionales ratificados por Espańa, pero no obliga a transponer exactamente al ordenamiento interno los distintos tipos de Derechos recogidos en cada texto legal».

49 La utilización de la expresión «vida privada» por el Tribunal Constitucional ha sido cuestionada por la doctrina por considerar que ambos enunciados contenidos en los arts. 18.1 CE y 8.1 CEDH no son coincidentes. La doctrina ha establecido que el único derecho fundamental recogido en la Constitución es el referido a la «intimidad personal y familiar» (Matia Portilla, 2011: 178 y 180). En tal sentido, se ha señalado que los términos «vida privada» y «vida íntima» no son coincidentes, ya que la intimidad constituye el núcleo «más privado» de la «vida privada» (González Trevijano, 1992: 130; Ruiz Miguel, 1995: 30). Sin embargo, hay quienes consideran que el art. $8 \mathrm{CEDH}$ tiene un contenido notablemente similar al del art. 18.1 CE por afirmarse que el derecho a la intimidad, incluida su dimensión familiar, recibe un tratamiento común en el Tribunal Constitucional y en el TEDH, por lo que el concepto de «vida privada» del CEDH debe considerarse equivalente o incluso indistinguible del de «intimidad personal»(Lezertua Rodríguez, 1996: 52-98). En el mismo sentido, Santolaya Machetti (2014: 429-430). 
partir de los años noventa, por una jurisprudencia constitucional que asegura que lo protegido por el art. 18.1 $\mathrm{CE}$ no es una intimidad determinada conforme a los usos sociales (dimensión objetiva del derecho a la intimidad), sino «el derecho a poseerla con independencia del contenido de aquello que se desea mantener al abrigo del conocimiento público» (dimensión subjetiva) ${ }^{50}$.

La distinción entre una y otra dimensión del art. 18.1 CE resulta, sin embargo, irrelevante en relación con el objeto protegido por el art. 18.2 CE. La razón estriba en que la inviolabilidad del domicilio es un derecho diferente con diferente objeto y contenido. Tiene una naturaleza formal, pues garantiza la inviolabilidad del ámbito — el espacio físico — pero no el desarrollo de vida íntima -o privada - en él. Tampoco asegura la vida íntima configurada según los usos sociales (material u objetiva), pues lo que identifica al espacio físico como domicilio constitucionalmente conforme no es su presumible o efectivo destino sino su carácter inviolable o intangible ${ }^{51}$. La inviolabilidad del espacio físico no se presume; describe el estado del espacio, de tal forma que un mismo espacio puede ser inviolable o no condicionado por elementos factuales de carácter temporal.

El art. 18.2 CE asegura la calidad de inviolable del espacio físico, por lo que la sola intervención - física o virtual — de este sin las debidas garantías vulnera su inviolabilidad ${ }^{52}$. Una vez vulnerado por la invasión, la revelación a terceros de lo observado o escuchado fruto de aquella violación o la transmisión de lo captado a través de medio técnico ya no quedan protegidas por las garantías del art. 18.2 CE, sino, en su caso, por otros derechos

50 SSTC 159/2009, 196/2006, 127/2003, 115/2000, 144/1999, y 134/1999. Sobre la evolución del significado del derecho fundamental a la intimidad personal y familiar, véanse Carrillo (2018: 410-412; Pardo Falcón, 2008: 520). Sobre la defensa de la concepción subjetiva del derecho fundamental a la intimidad, véase Villaverde Menéndez (2005: 328).

51 En este sentido, un establecimiento de atención al público es inviolable si está cerrado.

52 La calidad de inviolable del espacio físico y no su presumible o efectivo destino desarrollo de vida íntima o privada en él- determina que no sea necesario, diferenciar terminológicamente entre "domicilio» y «lugares cerrados» (art. 588 quater a.1. LOMLECrim), o entre "domicilio» y «espacios destinados al ejercicio de la privacidad» (art. 588 quater a.2. LOMLECrim), para exigir una misma autorización judicial de entrada en ellos. La razón estriba en que la aplicación de tal garantía para la delimitación restrictiva del art. 18.2 CE no depende de lo que signifiquen el «domicilio», los «espacios destinados al ejercicio de la privacidad» o los «lugares cerrados», sino de la verificación de la calidad de inviolable de cualquiera de estos espacios. 
fundamentales: derecho a la intimidad personal y familiar (art. 18.1 CE) o derecho a la imagen (art. 18.1 CE) ${ }^{53}$.

En puridad, se protege el espacio como soporte de privacidad, pero no como sostén del presumible o efectivo desarrollo de vida íntima o privada en él. Del mismo modo que el art. 18.3 CE asegura el proceso comunicacional a través de medio técnico entendido como soporte de privacidad, pero no como sostén de la efectiva comunicación a través de medio técnico entre emisor y receptor, o del carácter íntimo de la comunicación efectuada a su través.

La aplicación del art. 18.2 CE ha sido fluctuante. De un lado, el Tribunal Constitucional ha expresado que deben quedar al margen de la protección iusfundamental una gama de espacios físicos atendiendo a su efectivo o previsible destino: un almacén o local de negocio (oficina) ${ }^{54}$, un establecimiento hostelero ${ }^{55}$, un establecimiento comercial o local de negocio abierto al público $^{56}$, o «aquellos edificios o lugares que precisen de consentimiento de su titular» ex art. 91.2 LOPJ ${ }^{57}$.

Sin embargo, ha extendido su protección al analizar las garantías de la delimitación restrictiva de algunos de estos espacios inviolables: cuando no se presume su destino natural (oficina, local de negocio) ${ }^{58}$, o no se ha podido

53 De forma paradójica, el Tribunal Constitucional establece que, «a pesar de la autonomía que la Constitución Española reconoce a ambos derechos», la inviolabilidad del domicilio «constituye una manifestación de la norma precedente (art. 18.1 CE) que garantiza el derecho fundamental a la intimidad personal y familiar» (STC 189/2004).

54 STC 283/2000 y ATC 171/1989.

55 STC 283/2000. Sin embargo, la jurisprudencia del Tribunal Supremo ha identificado como domicilio un bar en el que los cotitulares viven habitualmente (STS 35/2018, de 24 de enero, Sala de lo Penal, Sección 1.a).

56 ATC 58/1992.

57 Es el antiguo art. 87.2 LOPJ, que se menciona en algunas sentencias del Tribunal Constitucional: 76/2002, 10/2002 y 283/2000. Sin embargo, esta protección resulta restrictiva si, como se ha dicho ya, tanto el art. 91.2 LOPJ como el art. 100.3 de la Ley 39/2015, de 1 de octubre, del Procedimiento Administrativo Común y de las Administraciones Públicas, garantizan la inviolabilidad de tales lugares o espacios que requieren el consentimiento del titular. Así pues, el art. 100.3 citado señala que, si fuese necesario entrar en ellos, «las Administraciones Públicas deberán obtener el consentimiento del mismo $o$, en su defecto, la oportuna autorización judicial».

58 AATC 58/1992, 272/1985 y 349/1998. En el ATC 58/1992, el Tribunal Constitucional, tras analizar la suficiencia de motivación de la autorización judicial, señala: «[...] todo ello sin entrar a considerar que tener por domicilio un local abierto al público supone confundir dos conceptos: el de domicilio, derecho público 
probar su carácter inviolable —establecimiento comercial en horario de cierre- ${ }^{59}$; también ha concedido el «beneficio de la duda» cuando no se ha conocido el efectivo destino del espacio — ser vivienda para el desarrollo de vida íntima, o local de negocio- ${ }^{60}$.

Similares fluctuaciones se observan también en la identificación de los «edificios o lugares cuyo acceso requiere el consentimiento del titular» (ex art. 91.2 LOPJ) como espacios inviolables, en unos casos, pero no en otros ${ }^{61}$; incluso vinculando la protección a la prueba de la existencia de vida privada ${ }^{62}$.

fundamental de personas físicas y jurídicas [...] y cualquier local cerrado (art. 87.2 LOPJ)», por lo que «el régimen aplicable al primero no es — ni tiene por qué serloextensible en su totalidad al segundo»). En otros casos, el Tribunal Constitucional ha analizado la existencia de garantías de la delimitación restrictiva del art. 18.2 CE sin cuestionar la naturaleza del espacio intervenido (un quiosco) (ATC 198/1991). El Tribunal Supremo ha seguido el mismo criterio en relación con otros espacios (trasteros no unidos a la vivienda, o almacenes destinados a guardar objetos). En este sentido, ha considerado que un trastero que no está unido a una vivienda no es un domicilio pese a la valoración sobre la existencia de autorización para la entrada en él (STS 279/2013, de 6 de marzo, Sala de lo Penal, Sección 1.a). También ha valorado la existencia de consentimiento de entrada en un bar, identificado como domicilio, no tanto por su carácter inviolable, sino por la constatación del efectivo desarrollo de vida íntima en él; es decir, por verificar que los dueños — un matrimonio- viven habitualmente en él. En definitiva, porque el espacio tenía por finalidad el desarrollo de vida íntima en él, más que por su carácter inviolable (STS 130/2018, de 24 de enero, Sala de lo Penal, Sección 1.a).

59 "[...] no existe certeza de que este local comercial pudiera estar abierto al público» (STC 69/1999).

60 STC 22/1984.

61 En unos casos, el Tribunal Constitucional no los ha considerado protegidos por las garantías del art. 18.2 CE (SSTC 10/2002 y 76/1992). Sin embargo, sí lo ha hecho en otros supuestos (STC 50/1995).

62 En ocasiones, el Tribunal Constitucional ha señalado que, si bien la entrada en «los edificios o lugares cuyo acceso requiera el consentimiento de su titular» no identificados como domicilio de conformidad con el antiguo art. 87.2 in fine LOPJ (en la actualidad, el art. 91.2 LOPJ) no quedaría protegida por el art. 18.2 CE, tal protección podía haberse llevado a cabo si el dueńo hubiera probado que en el espacio se desarrolla algún tipo de vida íntima, más que el estado de ruina que le provoca tal intervención: «[...] el propio Sr. Blázquez identificó expresamente ambos espacios como "locales" y, ya en el cuerpo del escrito, como "bar" y como "almacén”, existe la presunción de que no son domicilios, en el sentido expresado y protegido por el art. 18.2 CE. Por otro lado, la única alegación que en relación con ello se realiza tiende a demostrar no que se trataba de su domicilio, sino que la clausura del bar y del almacén 
El Tribunal Supremo ha seguido el mismo criterio que el Tribunal Constitucional vinculando el espacio protegido con su presumible o efectivo destino ${ }^{63}$.

implicarían "la pérdida de los medios de vida de mi representado y de su familia, a los que se conduce a la total ruina económica” (STC 283/2000).

63 En la línea establecida por el Tribunal Constitucional, ha vinculado la protección de algunos de estos espacios a su efectivo o presumible destino: «[...] no son domicilios legales sometidos a la protección constitucional los bares, los restaurantes, los almacenes y los garajes, siempre y cuando no conste espacialmente algún atisbo de privacidad; con la especial matización y excepción de aquellos casos en los que el garaje forme parte del domicilio como una habitación aneja, supuesto en el que el registro del garaje ha de acomodarse a las exigencias constitucionales del artículo 18.2» (STS 747/2015, de 19 de noviembre, Sala de lo Penal, Sección 1.a). En el mismo sentido, SSTS 35/2018, de 24 de enero, Sala de lo Penal, Sección 1.a; 924/2009, de 7 de octubre, Sala de lo Penal, Sección 1.a; 616/2005, de 12 de mayo; 282/2004, de 1 de marzo; 1431/1999, de 13 de octubre; 999/1997, de 27 de junio, y 123/1997, de 16 de diciembre. También ha señalado que la protección de algunos espacios (aseos) siguen la suerte del espacio principal en el que se ubican, por más que en ellos se desarrolle vida íntima: «La existencia en un establecimiento público de un aseo reservado para el titular del mismo o sus empleados, integrado en el mismo, no equivale a un ámbito de privacidad donde se desarrolla la vida de la persona, sino simplemente un lugar adecuado para determinadas necesidades, de forma que no es susceptible de alcanzar la protección que dispensa al domicilio la norma constitucional» (STC 450/2019, de 3 de octubre). En el mismo sentido se ha manifestado en la STC 146/2019, de 18 de marzo, Sala de lo Penal, Sección 1.a). La doctrina ha puesto de manifiesto la paradoja que supone la falta de protección domiciliar de los retretes, respecto de la construcción del derecho fundamental por la jurisprudencia del Tribunal Supremo (Rives Seva, 2004: 1440). Tal contradicción se observa en relación con otros espacios (camarotes) que sí quedan protegidos por el art. 18.2 CE aunque no lo sea el espacio principal en el que se ubican (un buque) (SSTS 720/2017,

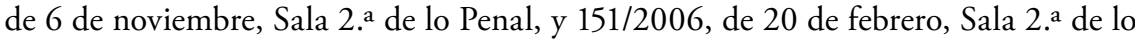
Penal). Desde 2017, el Tribunal Supremo ha identificado el domicilio con los espacios abiertos que forman un todo con la vivienda, «tanto por razón de la contigüidad espacial, como por la forma inequívoca de su delimitación, como por razón del destino». En tal sentido, ha asegurado el jardín o el patio pertenecientes a una vivienda (SSTS 146/2019, de 3 de marzo, Sala de lo Penal, Sección 1. ${ }^{\text {; }}$; 858/2018, de 13 de marzo, Sala de lo Penal, Sección 1.a; 113/2018, de 12 de marzo, Sala de lo Penal, Sección 1. ${ }^{\text {a) }}$, y 154/2017, de 10 de marzo, Sala de lo Penal, Sección 1. ${ }^{\mathrm{a}}$. También ha protegido los despachos profesionales (SSTS 974/2012, de 21 de noviembre, Sala de lo Penal, y 79/2012, de 9 de febrero de 2012, Sala de lo Penal, Sección 1.a), siguiendo al TEDH: STEDH de 13 de marzo de 2007, asunto Castravet contra 


\section{CONCLUSIÓN}

El art. 18.2 CE protege la inviolabilidad de un ámbito espacial de privacidad frente a la intervención de terceros. Asegura su carácter intangible, por lo que el domicilio constitucionalmente conforme se identifica con su inviolabilidad, y no con su presumible o efectivo destino — desarrollo de vida íntima o privada-.

La protección de la calidad de intangible del espacio físico evidencia una jurisprudencia constitucional restrictiva que protege solo algunos espacios inviolables. Pero fluctuante en otros casos, pues en ocasiones analiza la existencia de garantías de intervención de espacios a pesar de ser otro su presumible o efectivo destino. Es preciso reformular el objeto iusfundamental enunciado en el art. 18.2 CE con el fin de garantizar una protección más real y efectiva que alcance todos los espacios físicos que sean inviolables, con independencia de cuál sea su presumible o efectivo destino.

Los daños medioambientales provocados por una exposición prolongada a elevados niveles de saturación acústica que ponen en peligro la salud de los ciudadanos con la inacción u omisión de los poderes públicos no vulneran la inviolabilidad del domicilio ni el libre desarrollo de la vida privada domiciliar. Socavan, en realidad, el derecho fundamental a la integridad física y moral (art. $15 \mathrm{CE})$.

\section{BIBLIOGRAFÍA}

Aguado Renedo, C. (2011). Derecho a la integridad física y moral. En M. Aragón Reyes (dir.) y C. Aguado Renedo (coord.). Derechos fundamentales y su protección. Temas básicos de Derecho Constitucional, tomo III (pp. 140-148). Cizur Menor: Thomson Reuters.

Aragón Reyes, M. (1998). La inviolabilidad del domicilio. Revista Española de Derecho Constitucional, 54, 349-355.

Arruego Rodríguez, G. (2008). La naturaleza constitucional de la asistencia sanitaria no consentida y los denominados supuestos de «urgencia vital». Revista Española de Derecho Constitucional, 82, 53-82.

Bachmaier Winter, L. (2017). Registro remoto de equipos informáticos y principio de proporcionalidad en la Ley Orgánica 13/2015. Boletín del Ministerio de Justicia, 2195, 3-36.

Biglino Campos, P. (1997). Prólogo. En F. J. Matia Portilla. El derecho fundamental a la inviolabilidad del domicilio (pp. XXI-XXII). Madrid: McGraw-Hill.

Moldavia, y STEDH de 20 de junio de 2000, asunto Foxley contra Reino Unido). En el mismo sentido, véanse la STEDH de 22 de mayo de 2008, asunto Ililla Stelanor $c$. Bulgaria, y la STEDH de 16 de diciembre de 1992, asunto Niemietz c. Alemania. 
De Otto y Pardo, I. (1995). Derecho constitucional. Sistema de fuentes. Barcelona: Ariel.

Carrillo, M. (2018). Artículo 18.1. En P. Pérez Tremps y A. Saiz Arnaiz (dirs.). Comentario a la Constitución Española. 40 aniversario 1978-2018. Libro Homenaje a Luis López Guerra, t. I (pp. 405-418). Valencia: Tirant lo Blanch.

Díez Picazo, L. M. (2021). Sistema de derechos fundamentales. Valencia: Tirant lo Blanch.

Elvira Perales, A. (2019). Lista cerrada de derechos fundamentales. En R. Chueca Rodríguez (dir.). Las fronteras de los derechos fundamentales en la Constitución normativa (pp. 129-183). Madrid: Centro de Estudios Políticos y Constitucionales.

(2020). Derecho al secreto de las comunicaciones. En J. Matia Portilla y G. López de la Fuente (dirs.). De la intimidad a la vida privada y familiar. Un derecho en construcción (pp. 115-140). Valencia: Tirant lo Blanch.

González Trevijano, P. (1992). La inviolabilidad del domicilio. Madrid: Tecnos.

Jiménez Campo, J. (2018). Artículo 10.1 CE. En M. Rodríguez-Piñero, M. Bravo Ferrer y M. E. Casas Baamonde (dirs.). Comentarios a la Constitución Española (pp. 213-229). Madrid: Boletín Oficial del Estado.

Lascuraín Sánchez, J. A. (2018). Artículo 17.1. El derecho a la libertad. En M. RodríguezPiñero, M. Bravo Ferrer y M. E. Casas Baamonde (dirs.). Comentarios a la Constitución Española (pp. 447-509). Madrid: Boletín Oficial del Estado.

Lezertua Rodríguez, M. (1996). El derecho a la vida privada y familiar en la jurisprudencia del TEDH. Cuadernos de Derechos Judicial (ejemplar dedicado a: Perfiles del derecho constitucional a la vida privada y familiar) (pp. 52-98). Madrid: Consejo General del Poder Judicial.

López Menudo, F. (2009). La intervención del juez para la defensa del domicilio ¿Y también de la propiedad? Justicia Administrativa. Revista de Derecho Administrativo, 43, 5-44.

Matia Portilla, F. J. (1997). El derecho fundamental a la inviolabilidad del domicilio. Madrid: McGraw-Hill.

- (2011). Derecho a la intimidad. En M. Aragón Reyes (dir.) y C. Aguado Renedo (coord.). Derechos fundamentales y su protección. Temas básicos de Derecho Constitucional, tomo III (pp. 178-194). Cizur Menor: Thomson Reuters.

Navas Sánchez, M. M. (2011). ¿Inviolabilidad o intimidad domiciliaria? Revista de Derecho Político, 81, 155-197.

Pascual López, S. (2001). La inviolabilidad del domicilio en el derecho español. Madrid: Dykinson.

Pardo Falcón, J. (2008). Artículo 18.1 CE. Los derechos al honor, a la intimidad personal y familiar y a la propia imagen. En M. Rodríguez-Piñero, M. Bravo Ferrer y M. E. Casas Baamonde (dirs.). Comentarios a la Constitución Española. Conmemoración del XL aniversario de la Constitución (pp. 511-529). Madrid: Boletín Oficial del Estado.

Pérez Manzano, M. y Tomás-Valiente Lanuza, C. (2018). Artículo 15. En M. RodríguezPiñero, M. Bravo Ferrer y M. E. Casas Baamonde (dirs.). Comentarios a la Constitución Española, tomo I (pp. 375-411). Madrid: Boletín Oficial del Estado.

Rey Martínez, F. (2011). Derecho de propiedad privada. En M. Aragón Reyes (dir.) y C. Aguado Renedo (coord.). Temas básicos de Derecho Constitucional. Derechos fundamentales y su protección, tomo III (pp. 279-293). Madrid: Thomson Reuters.

Rives Seva, A. P. (2004). La diligencia de entrada y registro domiciliario. Barcelona: Bosch. 
Rodríguez de Santiago, J. M. (2018). Artículo 33. En M. Rodríguez-Piñero, M. Bravo Ferrer y M. E. Casas Baamonde (dirs.). Comentarios a la Constitución Española (pp. 11471175). Madrid: Boletín Oficial del Estado.

Ruiz Miguel, C. (1995). La configuración constitucional del derecho a la intimidad. Madrid: Tecnos.

Saldaña, M. N. (2012). «The right to privacy»: la génesis de la protección de la privacidad en el sistema constitucional norteamericano: el centenario legado de Warren y Brandeis. Revista de Derecho Político, 85, 195-239. Disponible en: https://doi.org/10.5944/ rdp.85.2012.10723.

Santolaya Machetti, P. (2014). El derecho a la vida privada y familiar (un contenido notablemente ampliado del derecho a la intimidad). En J. García Roca y P. Santolaya Machetti (coords.). La Europa de los derechos. El Convenio Europeo de Derechos Humanos (pp. 429-449). Madrid: Centro de Estudios Políticos y Constitucionales.

Villaverde Menéndez, I. (2005) Los datos de la propiedad y la propiedad de los datos. En F. J. Bastida Freijedo (coord.). Propiedad y Derecho Constitucional (pp. 315-346). Madrid: Colegio de Registradores de la Propiedad y Mercantiles de Espańa. 
